Tạp chí Khoa học và Công nghệ Biển T12 (2012). Số 4. Tr 88 - 97

\title{
ẢNH HƯỞNG ĐỊA HÌNH ĐÁY BIỂN LÊN DỊ THƯỜNG TRỌNG LỰC TRỂN KHU VỰC BIỄN ĐÔNG V̇̀̀ LÂN CẬN
}

\author{
TRÀN TUẤN DŨNG, NGUYỄN QUANG MINH, VŨ THU ANH
}

\section{Viện Địa chất và Địa Vật lý biển}

Tóm tắt: Áp dụng hiệu chỉnh trọng lực của địa hình đáy biển là vấn đề rất cần thiết và quyết định hiệu quả trong xủ lý, minh giải tài liệu trọng lưc biển. Trong nghiên cưu này, hiệu chỉnh trọng lưc của địa hình đáy biển đuợc tính toán kết hợp bằng các phuong pháp đura ra bởi Nagy (1966) và Kane (1962). Mô hình độ cao số địa hình đáy biển $(D E M)$ 2,5 × 2,5km được sử dụng trong quá trình tính toán hiệu chỉnh. Quá trình hiệu chinh được mở rộng đến khoảng cách tối uu là $100 \mathrm{~km}$ với mật độ trung bình đất đá vỏ trái đất $\rho_{r}=2,67 \mathrm{~g} / \mathrm{cm}^{3}$, mật độ lớp nước biển $\rho_{w}=1,03 \mathrm{~g} / \mathrm{cm}^{3}$. Kết quả hiệu chỉnh địa hình thu được trong toàn bộ khu vực biến đổi tù -17,95 đến +25,71mGal.

Với kết quả hiệu chỉnh địa hình, kết hợp cùng các nguồn số liệu khác, các tác giả đã xây dưng được một mang luới số liệu dị thường trọng lục Bughe đầy đủ với mạng luới 2,5 $\times 2,5 \mathrm{~km}$ cho khu vực Biển Đông và lân cận.

\section{MỞ ĐẦU}

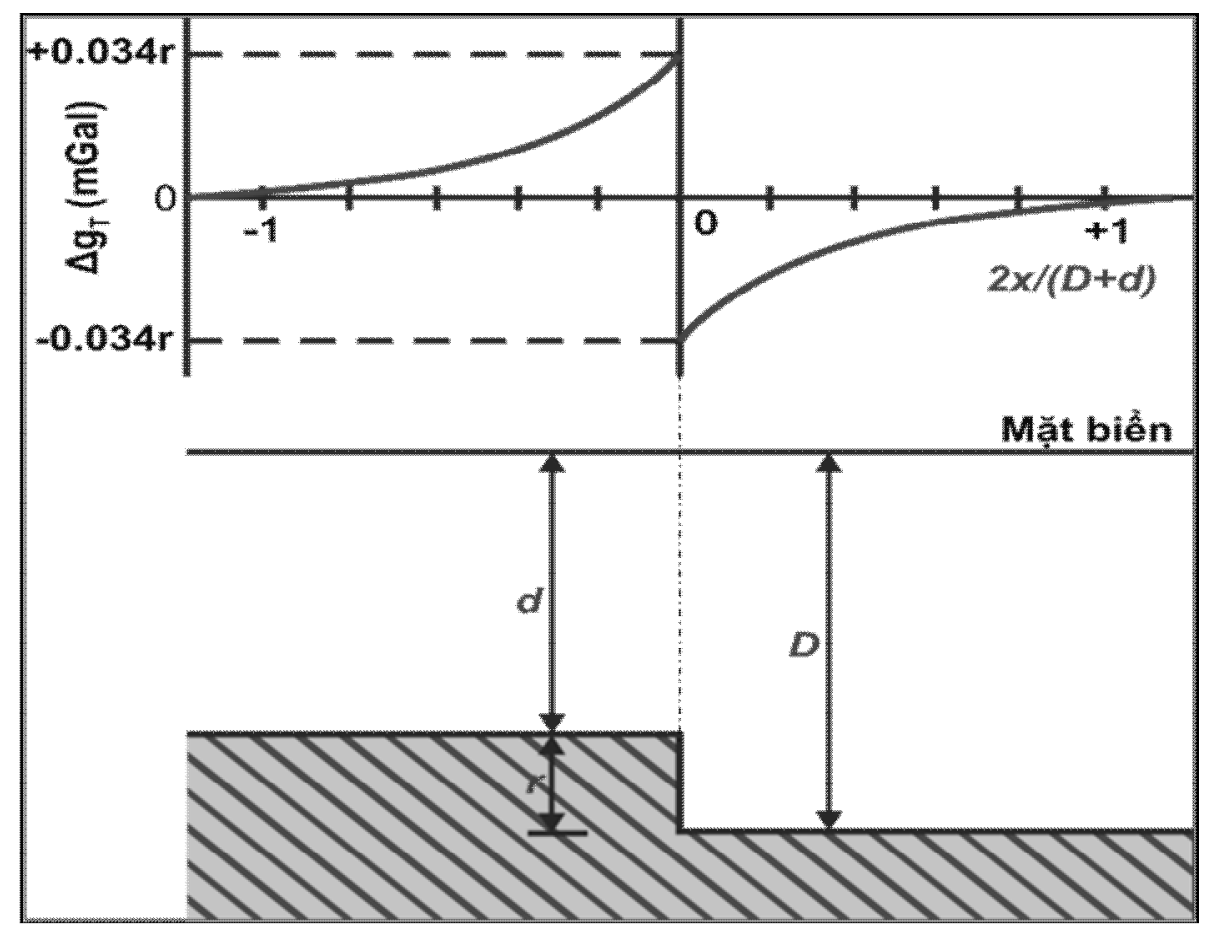

Hình 1. Mô hình hiệu chỉnh địa hình đáy biển (bậc thẳng đứng) với mật độ trung bình đất đá vỏ trái đất $\rho_{\mathrm{r}}=2,67 \mathrm{~g} / \mathrm{cm}^{3}$, mật độ lớp nước biển $\rho_{\mathrm{w}}=1,03 \mathrm{~g} / \mathrm{cm}^{3}, \mathrm{r}, \mathrm{d}, \mathrm{D}(\mathrm{m})$ [8] 
Nghiên cứu về ảnh hưởng của địa hình lên trường trọng lực, cho đến nay ở Việt Nam, mới chỉ được thực hiện một phần trên đất liền. Đối với khu vực Biển Đông, có thể nói hầu như chưa có một công trình nào về vấn đề đó được công bố. Vì một lẽ khu vực Biển Đông rất rộng lớn, các khảo sát về trọng lực, về độ sâu chưa được đầy đủ. Hơn nữa các nguồn số liệu chưa có sự đồng nhất cả về phân bố cũng như độ chính xác. Nếu chúng ta không áp dụng hiệu chỉnh địa hình, thì dị thường trọng lực sẽ chứa đựng có sai số do hiệu ứng địa hình gây ra, từ đó có thể dẫn đến sự minh giải sai về các cấu trúc địa chất bên trong vỏ trái đất.

Khảo sát lực trọng lực thường được chia ra thành ba loại: Khảo sát trên đất liền, khảo sát trên biển và khảo sát trên không. Trong mỗi loại hình khảo sát, ảnh hưởng của địa hình lên trường trọng lực được tính toán khác nhau. Hiệu chỉnh địa hình được sử dụng để bù hiệu ứng trọng lực do địa hình đáy biển gây ra vào dị thường trọng lực Bughe $[6,13]$. Trên đất liền, hiệu chỉnh địa hình luôn luôn có giá trị dương. Ngược lại, khác với trên đất liền, giá trị hiệu chỉnh địa hình trên biển mang giá trị âm hoặc dương phụ thuộc vào sự thay đổi của địa hình đáy biển xung quanh điểm đo (hình 1 ) [8]. Trên hình 1 là mô phỏng về hiệu chỉnh địa hình với khảo sát trọng lực trên biển.

\section{NGUỒN SỐ LIỆU SỬ DỤNG}

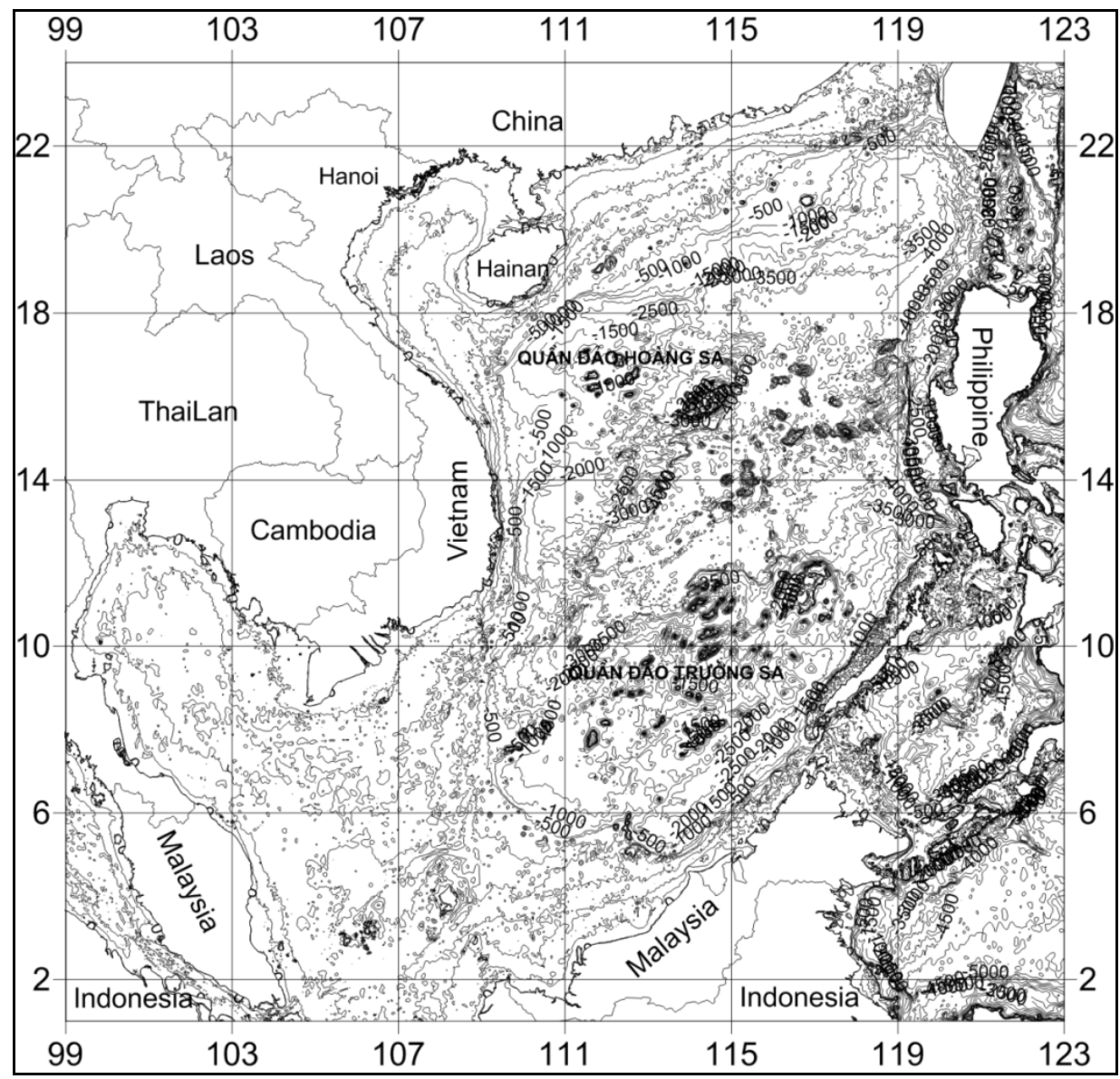

Hình 2. Độ sâu đáy biển (m) 


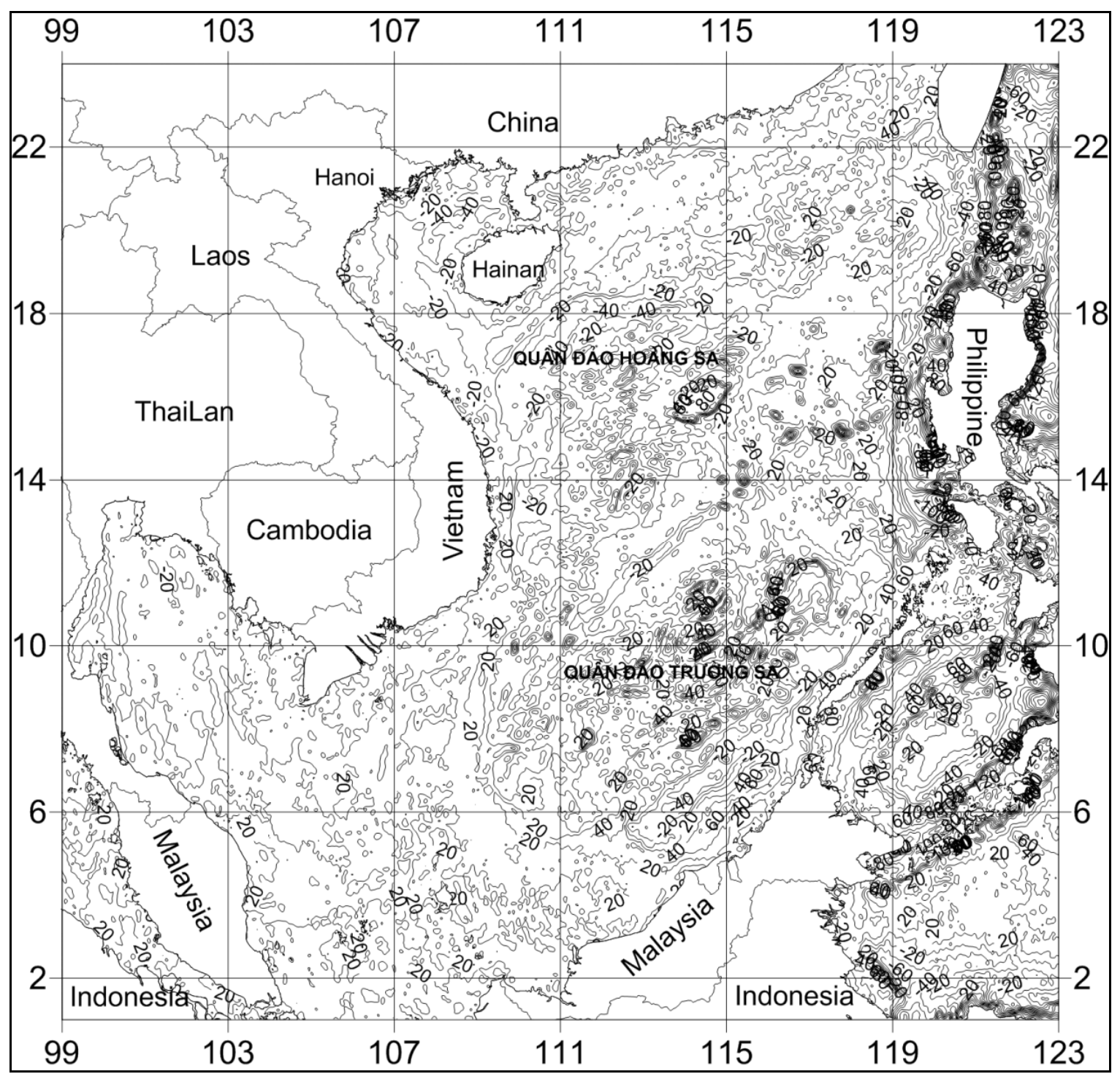

Hình 3. Dị thường trọng lực Fai (mGal)

Vùng biển và thềm lục địa Việt Nam đã có quá trình điều tra khảo sát về địa chất, địa vật lý liên tục trong hơn nửa thế kỷ qua với nhiều nguồn số liệu và kết quả điều tra nghiên cứu phong phú và đa dạng. Các nguồn số liệu địa vật lý đã được khai thác sử dụng cho nhiều mục đích như nghiên cứu cấu trúc địa chất, tìm kiếm thăm dò khoáng sản, quy hoạch xây dựng các công trình biển và ven biển, dự báo và phòng tránh thiên tai...

Cơ sở dữ liệu độ sâu đáy biển, dị thường trọng lực chủ yếu trên vùng biển Việt Nam là từ các chuyến đo trực tiếp trên biển của các công ty Địa vật lý Nga và Việt Nam trong những năm 90 thế kỷ trước, các nguồn số liệu đo thành tàu của các nước Pháp, Đức, Mỹ, Nhật và Việt Nam trong những năm tiếp theo. Trong các đề tài cấp nhà nước thuộc chương trình nghiên cứu biển do Viện Địa chất và Địa Vật lý biển chủ trì hoặc kết hợp cùng với Viện Dầu khí trong những năm qua như 48B-III-2 (1986-1990), KT-03-02 (1991-1995), KHCN-06-04 (1996-1998), KHCN-06-12 (1999-2000), KC-09-02 (2001- 
2005) đều thu thập, xử lý và bổ sung mới những kết quả nghiên cứu xác định trường địa vật lý rất có giá trị [2]. Đó là các nguồn tài liệu thu thập được từ các chuyến khảo sát bằng tàu của các công ty dầu khí Nga, Mỹ và phương tây trong giai đoạn điều tra khảo sát và tìm kiếm dầu khí trên thềm lục địa Việt Nam; Với những vùng biển sâu biển xa thì mạng lưới số liệu trọng lực vệ tinh 1' × 1' (V18.1) cũng như mạng lưới số liệu $2,5 \times 2,5 \mathrm{~km}$ độ sâu đáy biển [10] được khai thác sử dụng một cách hiệu quả trên vùng biển Việt Nam và lân cận ( xem hình 2, hình 3).

\section{PHƯƠNG PHÁP TÍNH TOÁN HIỆU CHİNH ĐỊA HİNH}

Hiệu chỉnh địa hình là phép hiệu chỉnh tốn nhiều thời gian tính toán nhất trong phương pháp trọng lực. Trong lịch sử, hiệu chỉnh địa hình được tính bằng cách sử dụng bảng palet Hammer [4] tại mỗi trạm đo. Tuy nhiên, hiệu chỉnh địa hình có thể được tính một cách hiệu quả trực tiếp từ lưới của mô hình DEM [5]. Ngày nay, đã có nhiều cải tiến đáng kể trong khả năng tính toán của máy tính điện tử, cùng với các dữ liệu địa hình dạng số thì thời gian tính hiệu chỉnh địa hình được rút ngắn một cách đáng kể.

Trong nghiên cứu này, hiệu chỉnh địa hình đáy biển được tính toán bằng cách sử dụng kết hợp các phương pháp được mô tả bởi Kane [5] và Nagy [7]. Hiệu chỉnh được tính toán dựa trên sự ảnh hưởng của các vùng gần, vùng trung gian và vùng $x a$ (hình 4) [3]. Sau đây là sơ đồ minh họa mô hình và các bước kỹ thuật trong quá trình tính toán:

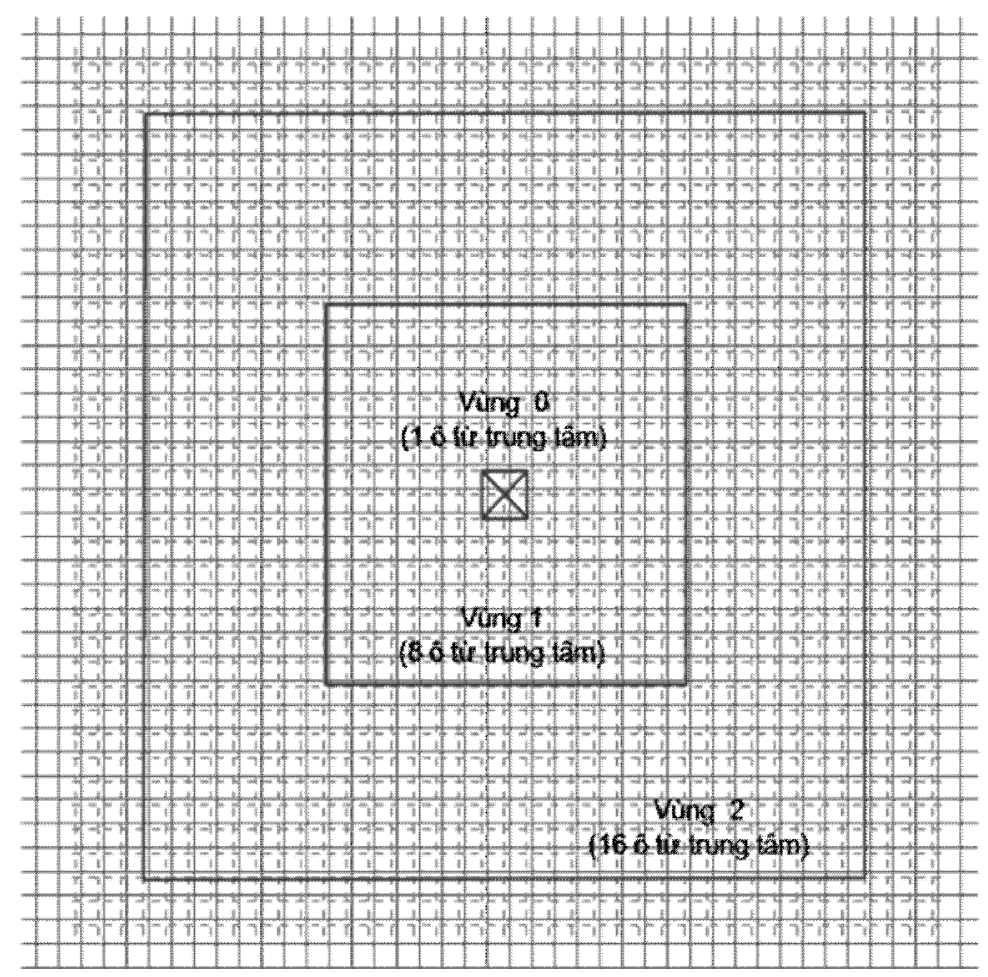

Hình 4. Sơ đồ phạm vi các vùng tính toán

(Luới đường gạch là luới được sủ dụng để tính toán hiệu chỉnh địa hình; Luới đường liền là luới mô hình DEM khu vưc) 


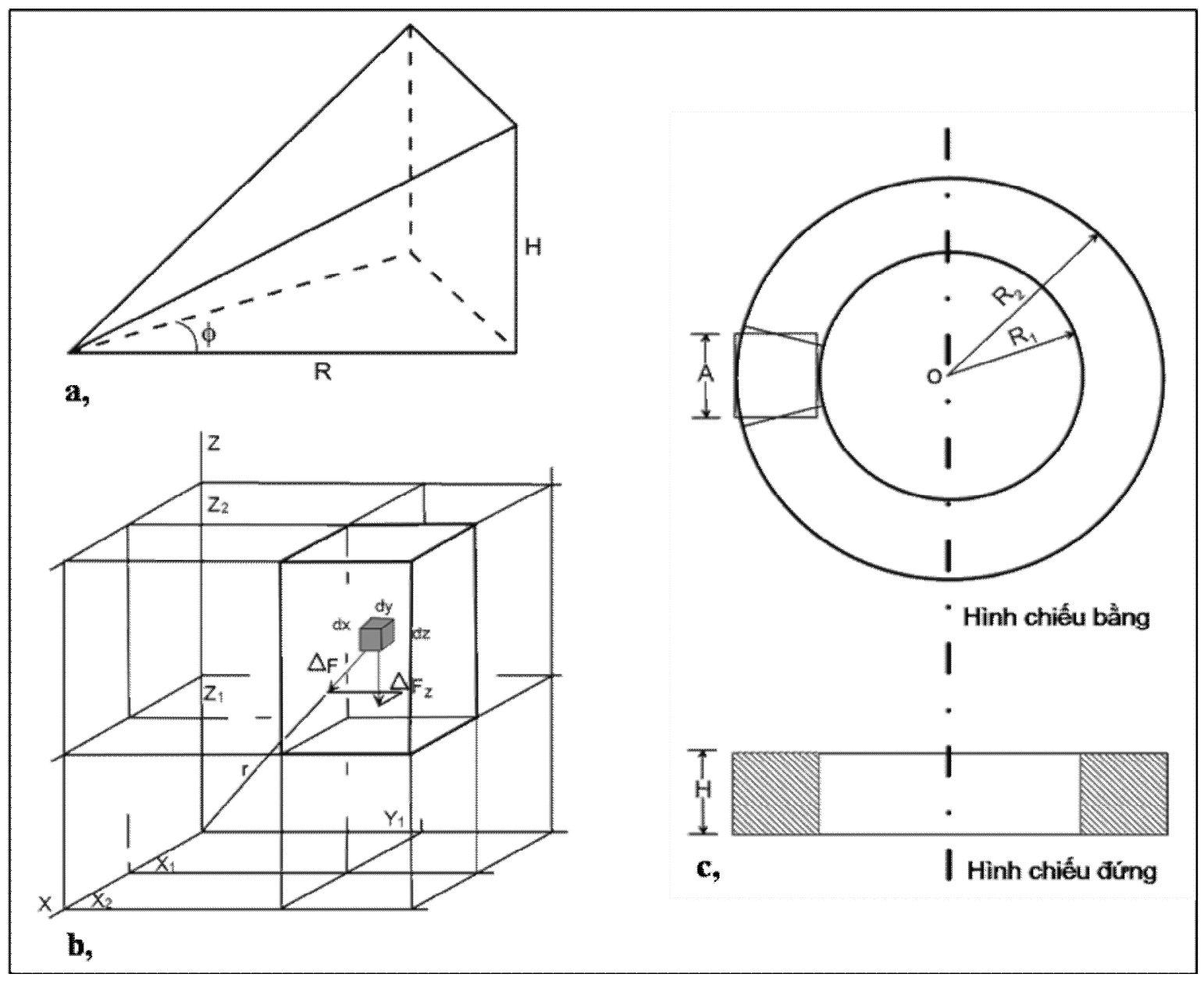

Hình 5. Mô phỏng mô hình tính hiệu chỉnh ảnh hưởng địa hình: $a>$ vùng $0 ; b>$ vùng 1 ;

$$
\text { c> vùng } 2
$$

Các công thức sử dụng để tính hiệu chỉnh địa hình cho các vùng cụ thể được mô tả như sau:

Vùng 0: Tam giác nghiêng (hình 5a)

$$
g=G D \phi\left(R-\sqrt{R^{2}+H^{2}}+\frac{H^{2}}{\sqrt{R^{2}+H^{2}}}\right)
$$

Trong đó: $\mathrm{g}$ - Lực hấp dẫn trọng lực; $\mathrm{G}$ - hằng số hấp dẫn; $\mathrm{D}$ - mật độ đất đá; $\mathrm{R}$ - khoảng cách lưới; $\mathrm{H}$ - khoảng cách giữa độ cao điểm đo và độ cao trung bình của ô cần tính.

Trong vùng gần ( 0 đến 1 ô từ điểm đo), hiệu ứng trọng lực lên điểm đo được tổng hợp từ hiệu ứng của bốn phần của lăng trụ tam giác (hình $5 \mathrm{a}$ ).

Vùng 1: Lăng trụ (hình 5b)

$$
g=-\left.G D\left|\begin{array}{l}
z_{2} \\
z_{1}
\end{array}\right| \begin{aligned}
& y_{2} \\
& y_{1}
\end{aligned}\right|_{x_{1}} ^{x_{2}} x \ln (x+r)+y \ln (x+r)+z \arctan \frac{z r}{x y} \| \mid
$$


Trong đó, $\mathrm{g}$ - Lực hấp dẫn trọng lực; $\mathrm{G}$ - hằng số hấp dẫn; $\mathrm{D}$ - mật độ đất đá; $\mathrm{r}$ - khoảng cách từ một đơn vị lăng trụ đến điểm đo.

Trong vùng 1 ( 1 đến 8 ô từ điểm đo), hiệu ứng địa hình tại mỗi điểm đo được tổng hợp bằng tổng hiệu ứng của các lăng trụ vuông đơn vị [7] (hình 5b).

Vùng 2 (và xa hơn): vùng hình khuyên (hình 5c)

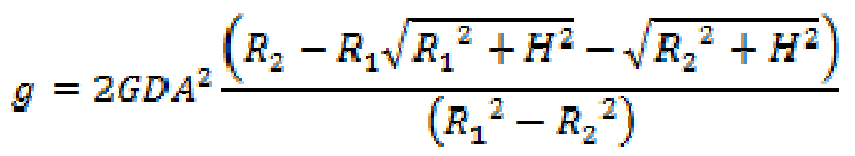

Trong đó, $\mathrm{g}$ - Lực hấp dẫn trọng lực; $\mathrm{G}$ - hằng số trọng trường; $\mathrm{D}$ - mật độ đất đá; $\mathrm{A}$ chiều dài bề ngang của lăng trụ; $\mathrm{R}_{1}, \mathrm{R}_{2}$ - bán kính vòng tròn trong và ngoài; $\mathrm{H}$ - chiều cao hình khuyên.

Trong vùng xa, hiệu ứng địa hình được tính toán dựa trên sự xấp xỉ đoạn hình khuyên như một lăng trụ vuông [5] (hình 5c).

\section{KẾT QUẢ VÀ THẢO LUẬN}

\section{Hiệu chỉnh địa hình}

Trên hình 6 là minh họa toàn bộ các bước hiệu chỉnh trọng lực địa hình đáy biển được thực hiện trong nghiên cứu này:

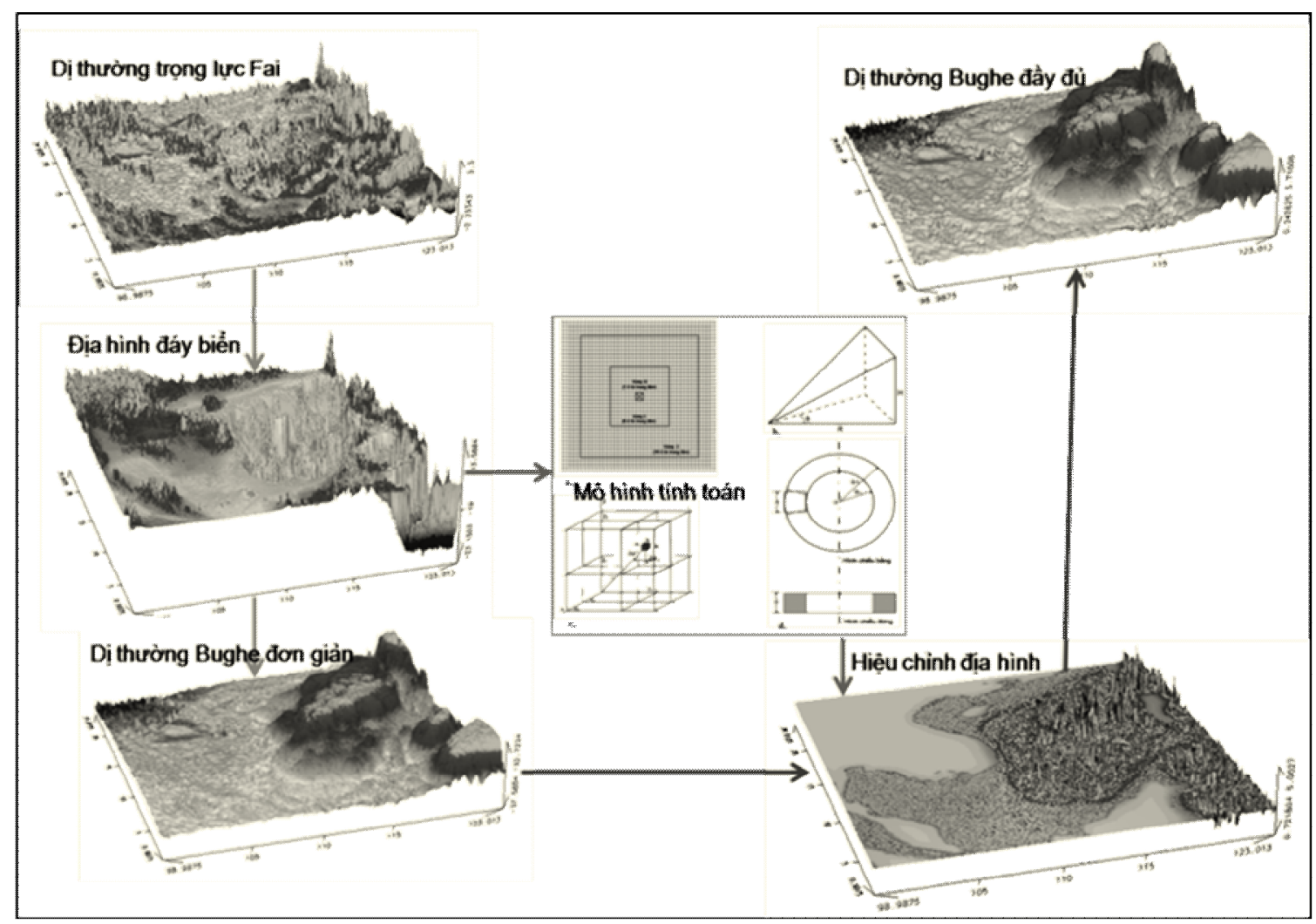

Hình 6. Minh họa quy trình tính hiệu chỉnh trọng lực địa hình 
Theo lý thuyết thì khoảng cách hiệu chỉnh địa hình lý tưởng là mở rộng đến vô cùng. Tuy nhiên để giảm thời gian tính toán, cần thiết phải xác định một khoảng cách ngoài hợp lý, nơi mà ảnh hưởng địa hình được coi là không đáng kể. Khoảng cách này phụ thuộc vào đặc điểm địa hình từng khu vực cụ thể. Trong nghiên cứu này đã tiến hành tính toán với nhiều khoảng cách khác nhau tăng dần từ bé đến lớn (từ 50 đến $200 \mathrm{~km}$ ). Sau khi so sánh sự biến đổi giá trị hiệu chỉnh ở các mức nói trên, các tác giả nhận thấy rằng khoảng cách mở rộng đến $100 \mathrm{~km}$ là tối ưu cho quá trình hiệu chỉnh ảnh hưởng địa hình (tại các khoảng cách xa hơn, hiệu chỉnh địa hình hầu như không có sự thay đổi đáng kể so với mức $100 \mathrm{~km}$ ).

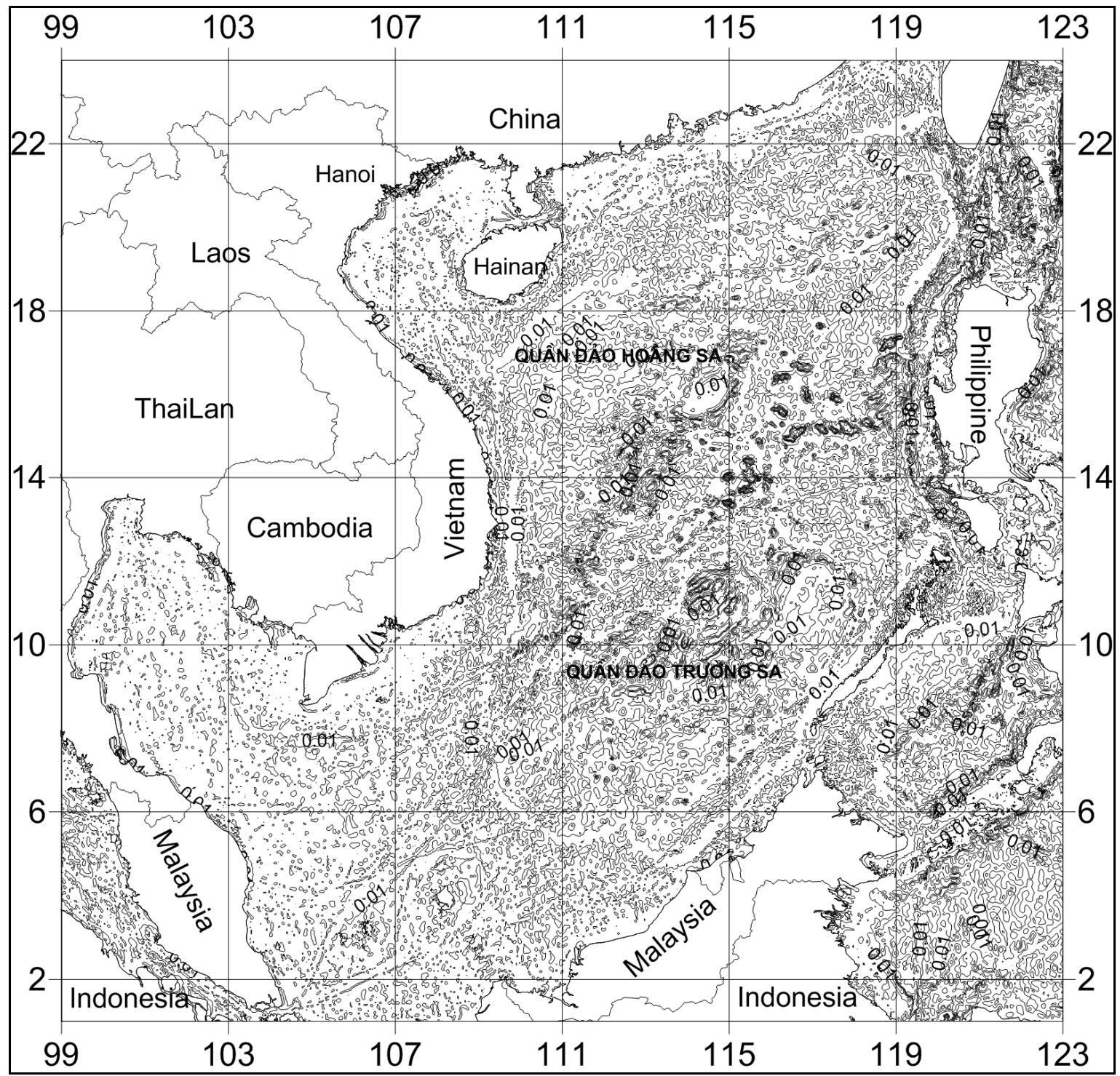

Hình 7. Giá trị hiệu chỉnh địa hình (mGal)

Kết quả tính toán hiệu chỉnh địa hình đáy biển được biểu diễn trên hình 7 . Hiệu chỉnh địa hình trong toàn bộ khu vực biến đổi từ $-17,95$ đến $+25,71 \mathrm{mGal}$. Giá trị hiệu chỉnh biến đổi mạnh tại những khu vực như trũng sâu, vùng quần đảo Hoàng $\mathrm{Sa}$, Trường $\mathrm{Sa}$, Luzon- 
ở đó địa hình đáy biển biến đổi rất mạnh mẽ. Trong khi đó tại những khu vực nước nông, nơi địa hình đáy biển bằng phẳng (khu vực vịnh Thái Lan, vịnh Bắc bộ) thì hiệu chỉnh địa hình gần như có giá trị bằng 0 (xem hình 7 , hình 8 ).

Để có một cái nhìn trực quan hơn về bức tranh phân bố giá trị hiệu chỉnh địa hình, một số tuyến cắt qua các khu vực đặc trưng được biểu diễn trên hình 8 :

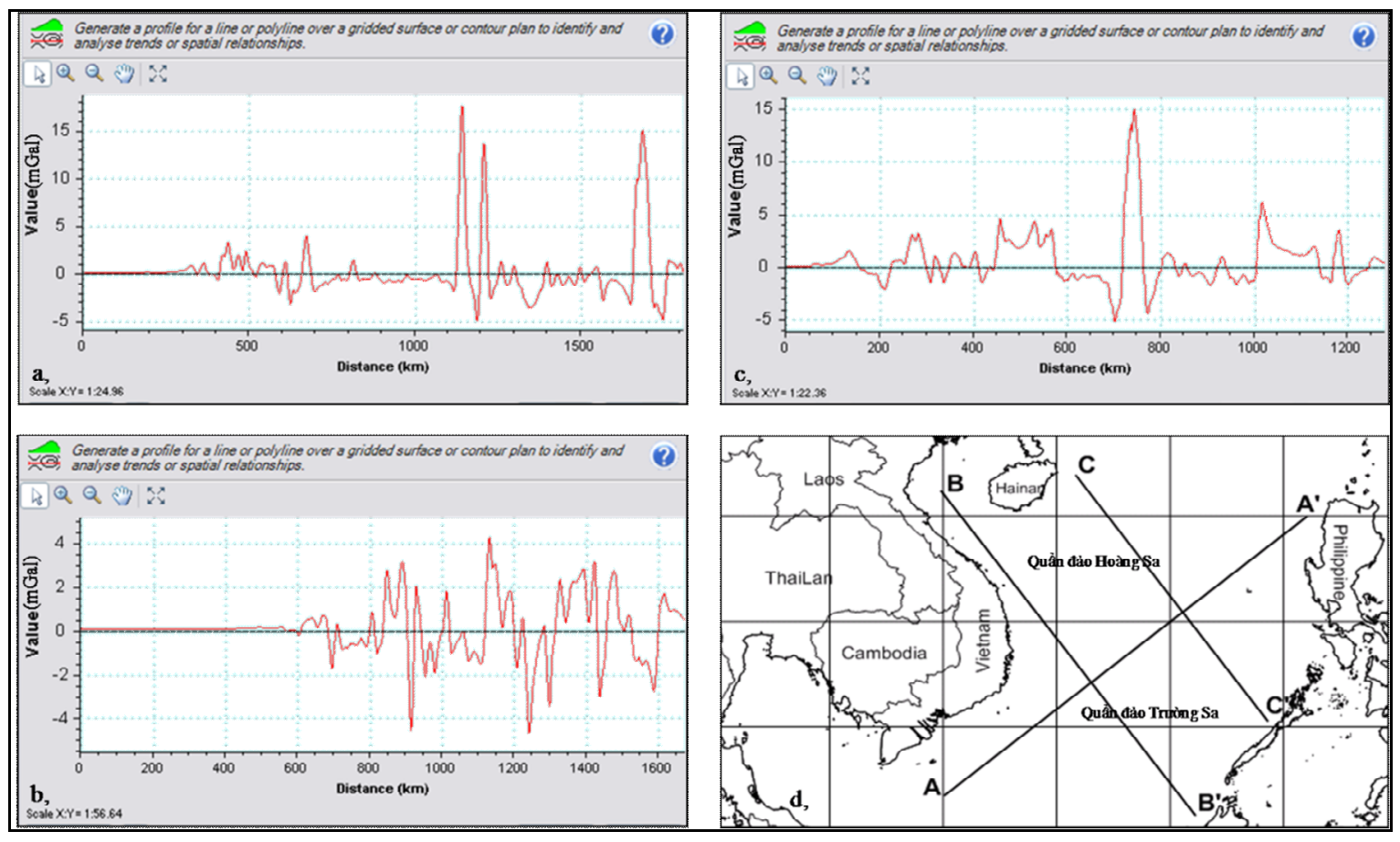

Hình 8. Các mặt cắt minh họa hiệu chỉnh địa hình (mật độ trung bình đất đá vỏ trái đất $\rho_{\mathrm{r}}=2,67 \mathrm{~g} / \mathrm{cm}^{\dot{3}}$, mật độ lớp nước biển $\left.\rho_{\mathrm{w}}=1,03 \mathrm{~g} / \mathrm{cm}^{3}\right)$; a> tuyến $\mathrm{AA}$ '; b> Tuyến BB'; c> Tuyến CC'; d>Sơ đồ tuyến

\section{Dị thường trọng lực Bughe đầy đủ}

Để tính dị thường trọng lực Bughe đầy đủ thì trước hết cần phải xác định được dị thường trọng lực Bughe đơn giản, chúng được tính như sau:

$$
\Delta \mathrm{g}_{\mathrm{ba}}=\Delta \mathrm{g}_{\text {fai }}+0,0419\left(\rho_{\mathrm{d}}-\rho_{\mathrm{n}}\right) \mathrm{h}
$$

Trong đó: $\Delta \mathrm{g}_{\mathrm{ba}}$ - dị thường trọng lực Bughe; $\Delta \mathrm{g}_{\text {fai }}$ dị thường trọng lực Fai; $\rho_{\mathrm{d}}=2,67 \mathrm{~g} / \mathrm{cm}^{3}$ là mật độ đất đá trung bình của vỏ trái đất, $\rho_{\mathrm{n}}=1,03 \mathrm{~g} / \mathrm{cm}^{3}$ là mật độ lớp nước biển và $\mathrm{h}$ độ sâu đáy biển.

Sau khi tính toán hiệu chỉnh địa hình thì dị thường trọng lực Bughe đầy đủ được xác định như sau:

$$
\Delta g_{c b}=\Delta g_{b a}+\Delta g_{\text {tc }}
$$

Trong đó, $\Delta \mathrm{g}_{\mathrm{ba}}$ - dị thường trọng lực Bughe đơn giản; $\Delta \mathrm{g}_{\mathrm{tc}}$ là hiệu chỉnh địa hình (xem hình 9). 


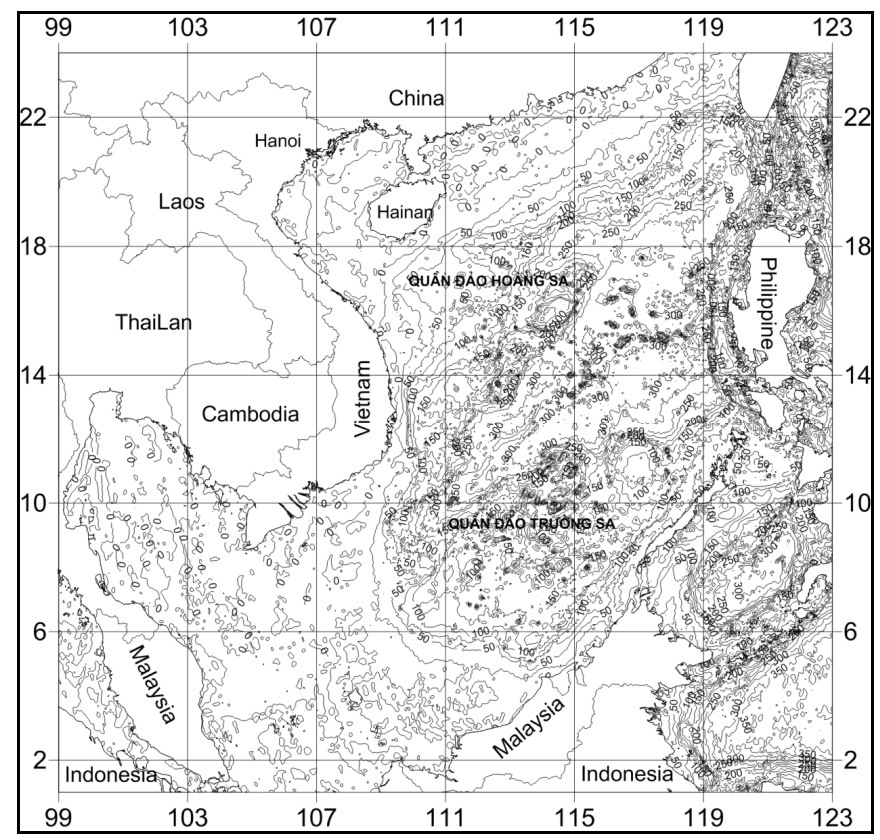

Hình 9. Dị thường trong lực Bughe đầy đủ (mGal) (đã có hiệu chỉnh địa hình)

\section{KẾT LUẬN}

Nghiên cứu ảnh hưởng của địa hình lên trường trọng lực, cho đến nay ở Việt Nam mới chỉ được thực hiện một phần trên đất liền. Đối với khu vực Biển Đông, có thể nói đây là công trình đầu tiên nghiên cứu về vấn đề đó được hoàn thành và công bố.

Áp dụng hiệu chỉnh trọng lực địa hình đáy biển là vấn đề rất cần thiết và hiệu quả trong xử lý, minh giải tài liệu trọng lực biển. Nếu không tính hiệu chỉnh thì dị thường trọng lực sẽ chứa đựng sai số do hiệu ứng địa hình gây ra, từ đó dẫ̂n đến sự minh giải sai về các cấu trúc địa chất bên trong vỏ Trái đất, đặc biệt là khi nghiên cứu ở những tỷ lệ lớn.

Trong nghiên cứu này, hiệu chỉnh trọng lực địa hình đáy biển được tính toán kết hợp bằng các phương pháp đưa ra bởi Kane [5] và Nagy [7]. Mô hình độ cao số địa hình đáy biển $(\mathrm{DEM}) 2,5 \times 2,5 \mathrm{~km}$ được sử dụng trong quá trình tính toán hiệu chỉnh. Quá trình hiệu chỉnh được mở rộng đến khoảng cách tối ưu là $100 \mathrm{~km}$ với mật độ trung bình đất đá vỏ trái đất $\rho_{\mathrm{r}}=2,67 \mathrm{~g} / \mathrm{cm}^{3}$, mật độ lớp nước biển $\rho_{\mathrm{w}}=1,03 \mathrm{~g} / \mathrm{cm}^{3}$. Kết quả hiệu chỉnh địa hình thu được trong toàn bộ khu vực biến đổi từ $-17,95$ đến $+25,71 \mathrm{mGal}$.

Với kết quả hiệu chỉnh địa hình thu được, kết hợp cùng các nguồn số liệu khác, các tác giả đã xây dựng được một mạng lưới số liệu $2,5 \times 2,5 \mathrm{~km}$ dị thường trọng lực Bughe đầy đủ cho toàn bộ khu vực Biển Đông và lân cận.

\section{TÀI LIỆU THAM KHẢO}

1. Bùi Công Quế, Trần Tuấn Dũng, Lê Trâm, 2008. Thành lập bản đồ dị thường trọng lực thống nhất trên vùng biển Việt Nam. Tạp chí Khoa học và Công nghệ Biển, T8, số 2, p. 29-41.

2. Bùi Công Quế và nnk., 2005. Xây dựng tập bản đồ những đặc trưng cơ bản về điều 
kiện tự nhiên và môi trường vùng biển Việt Nam và kế cận. Báo cáo tổng kết đề tài KHCN cấp nhà nước KC-09-02. Chương trình nghiên cứu biển KC-09.

3. Geosoft, 2009. Algorithm and Test Results from the Rio Tinto Valley, Spain.

4. Hammer, S., 1939. Terrain corrections for gravimeter stations. Geophysics, 4, 184-194.

5. Kane, M. F., 1962. A comprehensive system of terrain corrections using a digital computer. Geophysics, 27, 455-462.

6. LaFehr, T. R., 1998. On Talwani's "Errors in the total Bouguer correction". Geophysics, 63, 1131-1136.

7. Nagy, D., 1966. The gravitational attraction of a right rectangular prism. Geophysics, 31, 362-371.

8. Nettleton, L. L., 1971. Gravity and Magnetics for Geologists and Seismologists. Society of Exploration Geophysicists. No. 1, 121p.

9. Nguyễn Trọng Tín, Trần Tuấn Dũng và nnk, 2010. Đặc điểm kiến tạo các bể trầm tích Kainozoi ở Biển Đông Việt Nam trên cơ sở kết quả nghiên cứu mới. Tuyển tập Hội nghị Khoa học và Công nghệ quốc tế 35 năm ngành Dầu khí Việt Nam, tr. 57-73.

10. Sandwell, D. T., and Smith,W. H. F., 2009. Global marine gravity from retracked Geosat and ERS-1 altimetry: Ridge Segmentation versus spreading rate, J. Geophys. Res., 114, B01411, doi:10.1029/2008JB006008.

11. Tong, L. T., T. R. Guo, 2007. Gravity terrain effect of the seafloor topography in Taiwan. Terr. Atmos. Ocean. Sci., 18, 699-713, doi: 10.3319/TAO.2007.18.4.699(T).

12. Vanicek, P., P. Novak, and Z. Martinec, 2001. Geoid, topography, and the Bouguer plate or shell. J. Geodesy, 75, 210-215.

\title{
EFFECT OF THE SEAFLOOR TOPOGRAPHY TO GRAVITY ANOMALY IN THE EAST VIETNAM SEA AND ADJACENT AREAS
}

\author{
TRÀN TUẤN DŨNG, NGUYỄN QUANG MINH, VŨ THU ANH
}

\begin{abstract}
Summary:Gravity terrain correction of seafloor topography is very necessary and decisive for effective in interpretation of marine gravity data. In this study, gravity terrain correction is calculated in combination with the methods that given by Nagy (1966) and Kane (1962). A digital terrain model of the seafloor topography (DEM) $2.5 \times 2.5 \mathrm{~km}$ is used in the process of calculating terrain correction. The calculation of the terrain effect is extended to the optimal distance $100 \mathrm{~km}$ with average density of crustal rocks $\rho_{r}=2.67 \mathrm{~g} / \mathrm{cm}^{3}$, and sea water density $\rho_{w}=1.03 \mathrm{~g} / \mathrm{cm}^{3}$. The obtained result of the terrain correction changes from -17.95 to $+25.71 \mathrm{mGal}$ in the whole region.

By combining the above-mentioned terrain correction result with other data sources, the authors also have built a $2.5 \times 2.5 \mathrm{~km}$ grid of complete Bouguer gravity anomaly data for East Vietnam Sea and adjacent areas.
\end{abstract}

Ngày nhận bài: 22 - 9 - 2012

Người nhận xét:GS. TS. Bùi Công Quế 